\title{
The Fundamental Diagram in Vehicular Traffic ${ }^{\dagger}$
}

\author{
Alma Mendez \\ Universidad Autónoma Metropolitana-Cuajimalpa, Ciudad de México, Mexico \\ + Presented at the Entropy 2021: The Scientific Tool of the 21st Century, 5-7 May 2021; Available online: \\ https://sciforum.net/conference/Entropy2021/. \\ Published: 5 May 2021
}

Nowadays, the study of traffic flow in highways represents a big challenge. This problem is mainly interesting when vehicular density is high enough to produce congestion. The description of such phenomena has been made through several approaches going from the phenomenological up to individual behavior of drivers. In this work we start with a generalization of the Prigogine-HermanBoltzmann (PHB) kinetic equation to consider the vehicles' sizes, like the Enskog generalization to take into account the finite size of molecules in a moderately dense gas. Our main goal is the derivation of a fundamental diagram relating the flux with the density, in the homogeneous steady state of traffic. The conditions satisfied by the distribution function are given and their numerical solution allows the construction of the corresponding fundamental diagram. This derivation allows us to obtain some of the threshold values which separate the free and congested regimes. The model results are contrasted with recent empirical data and show excellent agreement.

(C) 2021 by the author. Licensee MDPI, Basel, Switzerland. This article is an open access article distributed under the terms and conditions of the Creative Commons Attribution (CC BY) license (http://creativecommons.org/licenses/by/4.0/). 